\title{
The Effect of Renal Perfusion Pressure on Renal Vascular Resistance in the Spontaneously Hypertensive Rat
}

\author{
Chen-Hsing Hsu and James M. Slavicek \\ Department of Internal Medicine, Nephrology Division, D 3238 South Ambulatory Care Building, The University of Michigan, \\ Ann Arbor, Michigan 48109, USA
}

\begin{abstract}
Renal hemodynamics and renal vascular resistance (RVR) were measured in the spontaneously hypertensive rat (SHR) and in the normotensive Wistar-Kyoto rat (WKY). In addition, the autoregulatory response and segmental RVR in the SHR were studied after aortic constriction. Mean arterial pressure (MAP) and RVR were higher in the SHR than in the WKY, but renal blood flow (RBF) and glomerular filtration rate were similar in both groups. Measurement of mean afferent arteriolar diameter (AAD) by a microsphere method showed a significantly smaller AAD in SHR $(17.7 \pm 0.35 \mu \mathrm{m})$ than in the WKY $(19.5 \pm 0.20 \mu \mathrm{m})$. This decrease in AAD could account for a $47 \%$ increase in preglomerular resistance. Aortic constriction in the SHR, sufficient to reduce renal perfusion pressure from 152 to $115 \mathrm{~mm} \mathrm{Hg}$,did not alter the AAD. Since RBF and glomerular filtration were also well maintained following aortic constriction, these autoregulatory responses suggest that vessels proximal to the afferent arteriole rather than postglomerular vasculature are primarily involved in the changes on intrarenal vascular resistance in SHR.
\end{abstract}

Key words: Spontaneously hypertensive rats - Renal blood flow - Renal vascular resistance - Afferent arteriolar diameter

\section{Introduction}

Renal vascular resistance (RVR) has been shown to be increased in spontaneously hypertensive rats (SHR). However, conflicting results regarding the intrarenal site of increased resistance have been obtained. Whereas some micropuncture studies have indicated that the afferent arteriole is the site of increased renal resistance in SHR [2], other research has indicated that both afferent and efferent vasculature may be involved [3]. In addition to these conflicting results, it should be noted that the estimations of afferent arteriolar resistance in previous studies were based on the assumption that the pressure drop between the renal artery and glomerular capillary is determined primarily by the afferent arterioles. However, recent studies by Kallskog et al. [13] and Tonder and Aukland [19] have suggested that other preglomerular vessels may also contribute to resistance in this portion of the renal vasculature.

The alterations of renal vascular resistance in SHR following reduced renal perfusion pressure have also been studied by several investigators, but conflicting results have

Send offprint requests to Chen-Hsing Hsu at the above address been obtained here as well. DiBona et al. [5] demonstrated that RVR of SHR increased, whereas Arendshorst et al. [2] found that RVR decreased following reduction of renal perfusion pressure by aortic constriction.

Despite numerous studies performed in regard to autoregulation of RBF and GFR, the basic roles of the afferent arteriole and other intrarenal vascular structures in the autoregulation process have not been directly evaluated. Direct evidence of afferent arteriolar resistance changes, a frequently postulated mechanism, has never been demonstrated. Furthermore, previous experiments have been carried out in anesthetized animals, although anesthesia is known to affect renal hemodynamics in various experimental conditions $[14,15,20]$.

In this experiment, we studied baseline renal vascular resistance as well as the alteration in resistance during reduction of renal perfusion pressure in spontaneously hypertensive rats (SHR). In addition, we employed a recently developed microsphere method $[8,9,16,17]$ to measure afferent arteriolar diameter before and after reduction of renal perfusion pressure by aortic constriction in conscious SHR. Normotensive Wistar Kyoto rats(WKY) were used as the comparison group.

\section{Methods}

Studies were performed in 11 week old male SHR and WKY animals (Charles River Breeding laboratories, Wilmington, MA, USA), which were given Purina rat chow and tap water ad libitum. Surgical preparation involved ether anesthesia and insertion of polyethylene catheters (P.E. 10) through the femoral artery into the aorta below the renal arteries, the right brachial artery into the thoracic aorta, and the right carotid artery into the left ventricle. In addition, the femoral vein was cannulated with a P.E. 50 tube for infusion purposes. A P.E. 50 tube was inserted through a small suprapubic incision into the bladder for urine collection. Aortic constriction was performed in SHR (AC-SHR) to reduce the renal arterial perfusion pressure. This was accomplished in SHR (ACSHR) by passing a ligature around the aorta at a point just proximal to the origin of the renal arteries. Mean arterial pressure was monitored (Gilson recorder and Statham transducer P23 Db) via the brachial artery and femoral artery catheters during aortic constriction of the ligature. The ligature was tightened until a gradient of approximately $25-35 \mathrm{~mm} \mathrm{Hg}$ existed between the pressures measured via the brachial artery catheter and the femoral artery catheter. This pressure gradient was well maintained after the animals recovered from the ether anesthesia. 
Following surgery, the rats were placed in restraining cages and allowed to recover for at least $120 \mathrm{~min}$ prior to beginning infusions for clearance studies. A priming dose of inulin in isotonic saline, $200 \mathrm{mg} / \mathrm{kg}$ body weight $(40 \mathrm{mg} / \mathrm{ml}$ of inulin), was administered and followed by a sustaining infusion at a rate of $0.02 \mathrm{ml} / \mathrm{min} / 100 \mathrm{~g}$ body weight. Inulin clearance $\left(C_{i n}\right)$ was started after a $30-40$ min equilibration period. Blood samples $(0.4 \mathrm{ml})$ were obtained at the beginning, middle, and end of a single $30-40 \mathrm{~min}$ urine collection.

At the end of the clearance period, approximately $3 \mathrm{~h}$ after the completion of surgery, cardiac output $(\mathrm{CO})$, renal blood flow (RBF), and afferent arteriolar diameter (AAD) were simultaneously measured in each rat with a microsphere method that has been previously described $[8,9]$. Radioactive microspheres $\left(15.1 \pm 3 \mu \mathrm{m}\right.$ diameter) labelled with ${ }^{85} \mathrm{Sr}$ were mixed with non-radioactive microspheres $(16.8 \pm 3$ and 22.3 $\pm 3 \mu \mathrm{m}$ ) in a proportion of 1:2:1 (mg ratio) giving a final concentration of $2 \mathrm{mg} / \mathrm{ml}$. The suspending solution was $10 \%$ dextran with $0.05 \%$ of Tween 80 . Approximately $0.10 \mathrm{ml}$ of the microsphere solution was injected into the left ventricle through the carotid catheter without any effect on arterial pressure. A free flow sample of blood was simultaneously obtained through the femoral catheter (approximately $0.1-$ $0.2 \mathrm{ml}$ ). The exact blood volume was determined by dividing the weight of the blood by the specific gravity of rat blood previously observed to be $1.061 \mathrm{~g} / \mathrm{ml}(N=10$. Immediately after the injection, the rats were anesthetized with pentobarbital, $20 \mathrm{mg} / \mathrm{kg}$ given intravenously, and the kidneys were removed within $30 \mathrm{~s}$. The kidneys were decapsulated and counted for radioactivity in a Packard Gamma Counter. The femoral blood sample was also counted.

Inulin was measured in duplicate with a method described previously [21], and clearances were calculated using standard techniques. $\mathrm{CO}$ and $\mathrm{RBF}$ were calculated using the following formulas:

$$
\begin{aligned}
\mathrm{CO}= & \frac{\text { total amount of isotope injected (counts } / \mathrm{min})}{\text { femoral blood (counts } / \mathrm{min})} \\
& \times \text { femoral blood flow rate }(\mathrm{ml} / \mathrm{min} / 100 \mathrm{~g} \text { body wt) }
\end{aligned}
$$

RBF was calculated for a single kidney or for two combined kidneys:

$$
\begin{aligned}
\mathrm{RBF}= & \frac{\text { kidney counts } / \mathrm{min}}{\text { femoral blood flow counts } / \mathrm{min}} \\
& \times \text { femoral blood flow }(\mathrm{ml} / \mathrm{min} / 100 \mathrm{~g} \text { body } \mathrm{wt})
\end{aligned}
$$

Renal plasma flow (RPF) was calculated as:

$\mathrm{RPF}=\mathrm{RBF} \times(1$-hematocrit $)$

Renal vascular resistance was calculated as: $\mathrm{RVR}=\mathrm{MAP} / \mathrm{RBF}$

Filtration fraction (FF) was calculated as: $\mathrm{FF} \%=\mathrm{C}_{\mathrm{in}} / \mathrm{RPF} \times 100 \%$

Afferent arteriolar diameter was estimated with the microsphere technique as previously described $[8,9,17]$. Basically, any microsphere with a diameter equivalent to the diameter of an afferent arteriole will be trapped within an afferent arteriole. Thus, the frequency distribution of the various sizes of microspheres trapped within afferent arterioles can be used to estimate afferent arteriolar diameter. After isotopic counting, the kidneys were serially placed in increasing concentrations of ethanol, cleared with methyl salicylate, and then embedded in Paraplast (Sherwood Medical, Inc., St. Louis, MO, USA). At least 16 to 20 sagittal sections $(110-120 \mu \mathrm{m}$ thickness), consisting of cortex and medulla from each kidney, were prepared using a microtome (American Optical 900). Each tissue slice was stained by immersion in $2 \%$ alcian blue for $15 \mathrm{~min}$. The stained tissue slices were dehydrated and cleared as described above and mounted in balsam (Supermount, Paragon S \& C, Inc., New York, USA) for light microscopic examination at $400 \times$. The vasculature and glomeruli could be readily identified in this transparent tissue preparation. Approximately one microsphere was found within a glomerulus or an afferent arteriole per 10 to 15 glomeruli examined.

A micrometer eyepiece with an accuracy of $0.2 \mu \mathrm{m}$ was used to measure the diameter of trapped microspheres. The diameters of at least 150 microspheres trapped within clearly identifiable afferent arterioles (AA) were measured for each rat. A microsphere was classified as trapped within an AA when more than half of the sphere was lodged beyond the entrance of the arteriole. Any microsphere trapped at the junction of an $\mathrm{AA}$ and glomerulus was excluded if more than half of the sphere had entered the glomerular bed. Microspheres were also excluded when: 1) more than one sphere was seen within the AA, 2) a spehere was trapped within an AA in association with occlusion of a preceding interlobular artery by a larger microsphere.

Histograms were constructed that depicted the distribution of the diameters of the trapped microspheres for each rat. Mean afferent arteriolar diameter was calculated using these diameter distributions according to the formula developed by Ofstad et al. [17]. This approach is based on a mathematical model which assumes that three factors determine the distribution of diameters of microspheres trapped within afferent arterioles in the kidney. These factors are: 1) the distribution of diameters of the injected microsphere population, 2) the distribution of diameters of the afferent arterioles, and 3) the afferent arteriolar blood flow, which is proportional to the fourth power of the AAD. The distribution of diameters of the injected microspheres and of the trapped microspheres is experimentally determined, while the afferent arteriolar blood flow is assumed to be proportional to the fourth power of the diameters of the trapped microspheres. Therefore, one can derive the distribution of diameters of the afferent arterioles.

Statistical calculations were performed with the Student $t$-test. The data were expressed as mean \pm SEM. The Smirnov-Kolmogorov test was used to determine the differences between the cumulated AAD frequency distributions of the control and experimental groups.

\section{Results}

Systemic and renal hemodynamics and clearance data are presented in Table 1. CO, RBF, and RPF were slightly lower in Sham-SHR and AC-SHR than in Sham-WKY; however, they were not statistically different. MAP monitored through the brachial catheter was significantly higher in SHR than WKY, whereas MAP monitored through the femoral catheter in SHR with aortic constriction (AC-SHR) was not different from control Sham-WKY. RVR of Sham-SHR was 
Table 1. Systemic and renal hemodynamics and inulin clearance of 11-week-old spontaneously hypertensive rats following aortic constriction and controls

\begin{tabular}{|c|c|c|c|c|c|c|c|c|c|}
\hline Experiment & $\begin{array}{l}\text { Body } \\
\text { wt g }\end{array}$ & $\begin{array}{l}\mathrm{CO} \\
\mathrm{ml} / \mathrm{min} / \\
100 \mathrm{~g}\end{array}$ & $\begin{array}{l}\mathrm{RBF}^{+} \\
\mathrm{ml} / \mathrm{min} / \\
100 \mathrm{~g}\end{array}$ & $\begin{array}{l}\mathrm{RPF} \\
\mathrm{ml} / \mathrm{min} / \\
100 \mathrm{~g}\end{array}$ & $\begin{array}{l}\text { MAP } \\
\text { mm Hg }\end{array}$ & & $\begin{array}{l}\text { RVR } \\
\mathrm{mm} \mathrm{Hg} / \mathrm{ml} / \\
\mathrm{min} / 100 \mathrm{~g}\end{array}$ & $\begin{array}{l}\mathrm{C}_{\text {in }} \\
\mathrm{ml} / \mathrm{min} / \\
100 \mathrm{~g}\end{array}$ & $\begin{array}{l}\mathrm{FF} \\
\%\end{array}$ \\
\hline I. WKY-Sham & 233.6 & 35.5 & 4.55 & 2.59 & 117.7 & 117.7 & 28.4 & 1.04 & 43.7 \\
\hline$N=7$ & \pm 2.9 & \pm 2.9 & \pm 0.68 & \pm 0.39 & \pm 3.0 & \pm 3.0 & \pm 4.0 & \pm 0.06 & \pm 4.6 \\
\hline II. SHR-Sham & 243.6 & 32.6 & 3.70 & 2.07 & 152.0 & 152.0 & $\overline{46.1}$ & 0.95 & $\overline{51.4}$ \\
\hline III. SHR-AC & 247.0 & 33.2 & 3.55 & 2.06 & 151.7 & 114.7 & $33.50^{*}$ & 0.90 & 43.5 \\
\hline$N=6$ & \pm 2.4 & \pm 4.0 & \pm 0.21 & \pm 0.12 & \pm 3.5 & \pm 5.0 & \pm 3.1 & \pm 0.08 & \pm 5.4 \\
\hline$P(\mathrm{I}-\mathrm{III})$ & $<0.01$ & NS & NS & NS & $<0.001$ & NS & NS & NS & $\overline{N S}$ \\
\hline
\end{tabular}

Abbreviations: $\mathrm{CO}$, Cardiac output; $\mathrm{RBF}^{+}$, Renal blood flow represents the average value of two kidneys; RPF, Renal plasma flow; MAP, Mean arterial pressure; RVR, Renal vascular resiatance; $\mathrm{C}_{\mathrm{in}}$, Inulin clearance of two kidneys combined; FF, Filtration fraction; B, Brachial catheter; F, Femoral catheter

* Significant at $P<0.05$ when compared to the value of SHR-Sham

Table 2. Renal blood flow, renal vascular resistance, afferent arteriolar diameter, and kidney weight of 11-week-old spontaneously hypertensive rats following aortic constriction and controls

\begin{tabular}{|c|c|c|c|c|}
\hline Experiment & $\begin{array}{l}\mathrm{RBF}^{++} \\
\mathrm{ml} / \mathrm{min} / 100 \mathrm{~g}\end{array}$ & $\begin{array}{l}\text { RVR } \\
\mathrm{mm} \mathrm{Hg} / \mathrm{ml} / \mathrm{min} / 100 \mathrm{~g}\end{array}$ & $\mathrm{AAD} \mu \mathrm{m}$ & Kidney wt. g \\
\hline I. WKY-Shan & 2.33 & 53.6 & 19.5 & 0.90 \\
\hline$N=7$ & \pm 0.24 & \pm 6.6 & \pm 0.20 & \pm 0.03 \\
\hline II. SHR-Sham & 1.93 & 88.9 & 17.7 & 1.07 \\
\hline$N=7$ & \pm 0.27 & \pm 12.2 & \pm 0.35 & \pm 0.04 \\
\hline$P(\mathrm{I}-\mathrm{II})$ & $\overline{\mathrm{NS}}$ & $<0.025$ & $<0.005$ & $<0.01$ \\
\hline III. SHR-AC & 1.92 & $61.0^{*}$ & 18.5 & 1.05 \\
\hline$N=6$ & \pm 0.14 & \pm 7.1 & \pm 0.27 & \pm 0.05 \\
\hline$P(\mathrm{I}-\mathrm{III})$ & $\overline{\mathrm{NS}}$ & $\overline{\mathrm{NS}}$ & $<0.01$ & $<0.01$ \\
\hline
\end{tabular}

Abbreviations: Same as in Table $1 . \mathrm{RBF}^{++}$represents the value of left kidney

* Significant at $P<0.05$ when compared to the value of SHR-Sham

significantly higher than that of Sham-WKY. RVR of ACSHR was slightly higher than that of Sham-WKY; however, they were not statistically different. $\mathrm{C}_{\mathrm{in}}, \mathrm{FF}$ and hematocrit were not different among the three groups of animals. The relatively high filtration fractions may have been associated with removal of blood for inulin measurement $(1.2 \mathrm{ml}$ blood) since the blood samples were not replaced. Because hydronephrosis was frequently found to involve the right kidney in SHR, measurement of AAD was obtained from left kidneys of all animals. Table 2 presents data of RBF, RVR, $A A D$, and weight of the left kidneys. RBF of left kidneys was not different among the three groups of animals. RVR of the Sham-WKY was significantly lower than that of Sham-SHR, but it was not different from the value of AC-SHR. RVR of Sham-SHR was significantly higher than that of AC-SHR $(P<0.05)$. Mean AAD of Sham-WKY was significantly larger than those of Sham-SHR and AC-SHR. However, despite a significant reduction in renal perfusion pressure the $\mathrm{RBF}$ and mean AAD of AC-SHR were not different from those of Sham-SHR. AAD was also calculated from the pooled frequency distributions of trapped microspheres for each group and examined with the two-sided SmirnovKolmogorov test. The results confirmed statistically significant differences between the AAD values of WKY and SHR.

\section{Discussion}

This study confirms previous reports that RVR is increased in SHR $[2,3,7]$. In addition, we have attempted to localize the site of increased renal resistance in SHR by measuring AAD using a microsphere technique. Although the microsphere method does not permit assessment of the interlobular or postglomerular vasculature, it does allow for measurement of AAD. Since the afferent arteriole has long been considered to play a major role in regulation of RVR, evaluation of its role in the increased RVR of SHR is of interest. Another advantage of the microsphere technique is that it can be applied to unanesthetized animals. This is of particular importance when one attempts to evaluate a hemodynamic system which can be readily affected by anesthesia $[14,15,18]$.

Before interpreting the intrarenal hemodynamic data obtained with the microsphere measurements, certain aspects of the technique itself should be considered. The microsphere method involves estimation of the diameter of the afferent arteriole in only one portion of the arteriole. If substantial tapering of the afferent arteriole exists, then the diameter obtained may not truly represent the mean diameter of the vessel. Morkrid et al. [16], however, have indicated that the tapering of the afferent arterioles is minimal in the dog. 
Another potential problem with the microsphere method involves the tendency for spheres to be preferentially directed towards the outer cortex due to an axial streaming effect. Therefore, the results of AAD may be somewhat weighted towards representation of outer cortical nephrons versus inner cortical nephrons. Finally, there is a possibility that microsphere occlusion of an afferent arteriole results in a local autoregulatory effect which dilates the vessel. The microsphere would pass further along the arteriole and an overestimation of AAD could result.

The result of these experiments reflects that the mean AAD of 11-week-old SHR is significantly smaller than the mean AAD of age-matched WKY control rats. Although the measurements of AAD in this study were performed $3 \mathrm{~h}$ after completion of surgery in animals known to have increased sympathetic activity $[4,11,12]$, the observed difference in AAD cannot be attributed to the surgical trauma. We have previously reported that AAD is significantly smaller in both 8 and 12-week-old SHR than in control age-matched WKY with less surgical stress [10].

Micropuncture studies performed by Arendshorst and Beierwaltes [2] have indicated that the altered RVR in SHR involves only the preglomerular vasculature. In contrast to the studies of Arendshorst and Beierwaltes, studies by Azar et al. [3] have indicated that increased postglomerular resistance as well as increased preglomerular resistance may be playing a role in the increased RVR of SHR. Since resistance is inversely proportional to the fourth power of the vessel radius, in the present study one can estimate the change in resistance that could result from the decreased AAD observed in SHR. Accordingly, the decrease in AAD of 11-week-old SHR is sufficient to account for a $47 \%$ increase in preglomerular resistance.

After reduction of renal perfusion pressure in SHR by aortic constriction, total RVR decreased and RBF was well maintained. These findings are consistent with the demonstration by Arendshorst [1] that autoregulation of RBF in SHR can occur within the perfusion pressure range of 105 to $165 \mathrm{~mm} \mathrm{Hg}$. This autoregulatory response does not appear to involve the afferent arteriole since the mean AAD of SHR following aortic constriction was not different from the AAD of sham-SHR. Since AAD did not change during autoregulation of RBF and the glomerular filtration was well preserved following aortic constriction, these autoregulatory responses suggest that the preglomerular vasculature (specifically interlobular artery) rather than the postglomerular vasculature is primarily involved in the resistance changes. However, this interpretation cannot be firmly established without simultaneous evaluation of the other factors that influence glomerular filtration, e.g. glomerular permeability and tubular pressure.

Although the results of this study and those of Arendshorst et al. [2] have indicated that autoregulation of RBF by SHR is possible, not all investigators have arrived at this conclusion. For example, DiBona et al. $[5,6]$ have failed to demonstrate autoregulation of RBF with renal perfusion pressure ranging from $110-130 \mathrm{mmHg}$. They have also reported that RVR increases following reduction of real perfusion pressure in SHR [5]. These investigators attributed the increased RVR entirely to efferent arteriolar vasoconstriction [5].
Acknowledgement. This work was supported by a grant-in-aid from the American Heart Association and with funds contributed in part by the Michigan Heart Association

\section{References}

1. Arendshorst WJ (1979) Autoregulation of renal blood flow in spontaneously hypertensive rats. Circ Res 44:344-349

2. Arendshorst WJ, Beierwaltes WH (1979) Renal and nephron hemodynamics in spontaneously hypertensive rats. Am J Physiol 236:F246-251

3. Azar S, Johnson MA, Scheinman J, Bruno L, Tobian L (1979) Regulation of glomerular capillary pressure and filtration rate in young Kyoto hypertensive rat. Clin Sci 56:203-209

4. Coote JH, Sato Y (1977) Reflex regulation of sympathetic activity in spontaneously hypertensive rats. Circ Res 40:571-577

5. DiBona GF, Rios LL (1976) Mechanism of exaggerated diuresis in spontaneously hypertensive rats. Am J Physiol 235:F409-F416

6. DiBona GF, Rios LL (1977) Autoregulation of renal blood flow in spontaneously hypertensive rats. Proc Ann Meet Am Soc Nephrol, 10th, Washington, DC, (Abstract) p 46A

7. Fink GD, Brody MJ (1979) Renal vascular resistance and reactivity in the spontaneously hypertensive rat. Am J Physiol 237:F128F132

8. Hsu CH, Kurtz TW, Sands CF (1979) Intrarenal vascular resistance in glycerol-induced acute renal failure in the rat. Circ Res 45:583587

9. Hsu CH, Slavicek JM (1980) Renal vascular resistance (RVR) in spontaneously hypertensive rats (SHR). Proc Ann Meet Am Soc Nephrol, 13th, Washington, DC (Abstract) p 61A

10. Hsu CH, Kurtz TW, Slavicek JM (1980) Effect of exogenous angiotensin 11 on renal hemodynamics in awake rat. Measurement of afferent arteriolar diameter by the microsphere method. Circ Res $46: 646-650$

11. Judy WV, Farrell SK (1979) Arterial baroreceptor reflex control of sympathetic nerve activity in the spontaneously hypertensive rat. Hypertension 1:605-614

12. Judy WV, Watanabe AM, Henry DP, Besch HR, Murphy WR, Hockel GM (1979) Sympathetic nerve activity: Role in regulation of blood pressure in the spontaneously hypertensive rat. Circ Res 38, Suppl $1: 21-29$

13. Kallskog O, Lindbom LO, Ulfendahl HR, Wolgast M (1976) Hydrostatic pressures within the vascular structures of rat kidney. Pflügers Arch 363:205-210

14. Koeppen BM, Katz AI, Lindheimer MD (1979) Effect of general anesthesia on renal hemodynamics in the rat. Clin Sci 57:469-471

15. Linas SL, Berl T, Aisenbrey GA, Better OS, Anderson RJ (1980) The effect of anesthesia on hemodynamics and renal function in the rat. Pflügers Arch 384:135-141

16. Morkrid L, Ofstad J, Willassen Y (1978) Diameter of afferent arterioles during autoregulation estimated from microsphere data in the dog. Circ Res 42:181-191

17. Ofstad $J_{2}$ Morkrid L, Willassen $Y$ (1975) Diameter of the afferent arteriole in the kidney estimated with microsphere method. Scand J Clin Lab Invest 35:767-774

18. Smith TL, Hutchins PM (1980) Anesthetic effects on hemodynamics of spontaneously hypertensive and Wistar-Kyoto rats. Am J Physiol 238: H539- H544

19. T $\phi$ nder KJH, Aukland $\mathrm{K}$ (1979/80) Interlobular arterial pressure in the rat kidney. Renal Physiol 2:214-221

20. Vatner SF (1974) Effects of hemorrhage on regional blood flow distribution in dogs and primates. $J$ Clin Invest 54:225-235

21. Walser M, Davidson DG, Orloff J (1955) The renal clearance of alkalistable inulin. J Clin Invest 34:1520-1523

Received July 24, 1981/Accepted February 3, 1982 